\title{
The ABC Transporter BcatrB Affects the Sensitivity of Botrytis cinerea to the Phytoalexin Resveratrol and the Fungicide Fenpiclonil
}

\author{
H. Schoonbeek, ${ }^{1}$ G. Del Sorbo, ${ }^{2}$ and M. A. De Waard ${ }^{1}$ \\ ${ }^{1}$ Laboratory of Phytopathology, Wageningen University, P.O. Box 8025, 6700 EE, Wageningen, \\ The Netherlands; '2Department ARBOPAVE, Plant Pathology Section, Via Università, 100, 80055 Portici \\ (Naples), Italy \\ Accepted 22 November 2000.
}

\begin{abstract}
During pathogenesis, fungal pathogens are exposed to a variety of fungitoxic compounds. This may be particularly relevant to Botrytis cinerea, a plant pathogen that has a broad host range and, consequently, is subjected to exposure to many plant defense compounds. In practice, the pathogen is controlled with fungicides belonging to different chemical groups. ATP-binding cassette (ABC) transporters might provide protection against plant defense compounds and fungicides by ATP-driven efflux mechanisms. To test this hypothesis, we cloned BcatrB, an ABC transporter-encoding gene from $B$. cinerea. This gene encodes a 1,439 amino acid protein with nucleotide binding fold (NBF) and transmembrane (TM) domains in a [NBF$\left.\mathrm{TM}_{6}\right]_{2}$ topology. The amino acid sequence has 31 to $67 \%$ identity with $\mathrm{ABC}$ transporters from various fungi. The expression of BcatrB is up regulated by treatment of $B$. cinerea germlings with the grapevine phytoalexin resveratrol and the fungicide fenpiclonil. BcatrB replacement mutants are not affected in saprophytic growth on different media but are more sensitive to resveratrol and fenpiclonil than the parental isolate. Furthermore, virulence of $\Delta$ BcatrB mutants on grapevine leaves was slightly reduced. These results indicate that BcatrB is a determinant in sensitivity of $B$. cinerea to plant defense compounds and fungicides.
\end{abstract}

The widely occurring plant pathogenic fungus Botrytis cinerea Pers.:Fr., anamorph of Botryotinia fuckeliana (De Bary) Whetzel, infects the fruits, flowers, or green tissues of at least 235 plant species (Jarvis 1977). Several of these hosts are known to produce defense compounds belonging to various chemical classes that act as constitutive or inducible chemical barriers (Osbourn 1999). B. cinerea is able to withstand toxic effects of plant defense compounds with varying structures such as stilbenes, isoflavonoids, coumarins, and sesquiterpenes. Pathogens can overcome the defense of their hosts by specific mechanisms such as enzymatic conversion of these

Corresponding author: M. A. De Waard; Telephone: +31 3174831 23; Fax: +31 3174834 12; E-mail: maarten.dewaard@ fyto.dpw.wag-ur.nl

Nucleotide sequence of BcatrB was assigned EMBL accession no. AJ006217. compounds (Schafer et al. 1989). The specificity of such enzymes might delimit the host range of pathogens. More general mechanisms that provide protection against a broad range of toxicants such as compartmentalization and reduction of accumulation would allow pathogens to cope with various defense compounds that occur in many different host species. Reduction of accumulation can be achieved with active efflux by ATP-binding cassette (ABC) transporters. These transporters accept various classes of secondary plant metabolites as substrates (Kolaczkowski et al. 1998).

The superfamily of $\mathrm{ABC}$ transporters consists of membrane-bound proteins with an ATP-binding cassette (Higgins 1992). They use ATP to transport a wide spectrum of compounds over various membranes (Senior et al. 1995). Several subfamilies can be distinguished on the basis of the topology of hydrophobic domains made up of transmembrane helices (TM) and hydrophilic domains, comprising the nucleotide binding fold (NBF). The latter is characterized by the common nucleotide binding motifs, described by Walker et al. (1982), and the typical ABC signature. Some subfamilies of ABC transporters are named after their first-known member with a function in multidrug resistance (MDR). For instance, they can confer MDR to mammalian cancer cells causing resistance to unrelated drugs used in chemotherapy. In mammals, MDR can be mediated by overexpression of two subfamilies of $\mathrm{ABC}$ transporters, the P-glycoprotein or MDR1-like ABC transporters with a $\left[\mathrm{TM}_{6}-\mathrm{NBF}\right]_{2}$ topology, and the MDRrelated proteins $\mathrm{MRP}$ with a $\mathrm{TM}_{\mathrm{n}}-\left[\mathrm{TM}_{6}-\mathrm{NBF}\right]_{2}$ topology (Ishikawa et al. 1997). In Saccharomyces cerevisiae, a pleiotropic drug resistance (PDR) network is involved in MDR (Balzi and Goffeau 1995). The PDR network is composed of transcriptional regulators such as PDR1 and PDR3 that activate expression of many genes, including PDR5 and $S N Q 2$, PDR-like $\mathrm{ABC}$ transporters with a $\left[\mathrm{NBF}-\mathrm{TM}_{6}\right]_{2}$ topology. $\mathrm{ABC}$ transporters with additional topologies have been described in S. cerevisiae (Decottignies and Goffeau 1997). Transporters in the PDR network provide $S$. cerevisiae with tolerance to different toxic compounds. This manifests itself as increased sensitivity upon disruption of one or more members of the network. ABC transporters present in $S$. cerevisiae can export a multitude of compounds comprising plant secondary metabolites (Kolaczkowski et al. 1998). For this reason, $\mathrm{ABC}$ transporters of plant pathogens could play a significant 
role in pathogenesis by protecting against plant defense compounds or preventing suicidal effects of fungal toxins (De Waard 1997). Recently, this hypothesis was confirmed by the finding that the $\mathrm{ABC}$ transporter $A B C l$ from Magnaporthe grisea is involved in pathogenesis on rice because disruption of the $A B C 1$ gene results in strongly reduced virulence (Urban et al. 1999). No substrate has yet been identified for Abc1, although it was proposed that this protein is involved in protection against unidentified plant defense compounds.

$\mathrm{ABC}$ transporters in filamentous fungi also can be involved in protection against fungicides. In Aspergillus nidulans strains selected for resistance to azole fungicides, crossresistance to unrelated compounds has been observed (Van Tuyl 1977). Resistance to azoles correlated with decreased accumulation as a result of increased energy-dependent efflux of these toxicants (De Waard and Van Nistelrooy 1979; De Waard and Van Nistelrooy 1980). It is hypothesized that ABC transporters account for this increased efflux activity (De Waard 1997). These azole-resistant mutants of A. nidulans indeed display increased expression of particular ABC transporter genes (Del Sorbo et al. 1997). Similarly, azole-resistant isolates of Penicillium digitatum overexpressed the ABC transporter PMR1 and disruption of the encoding gene reduced resistance of these mutant strains to these compounds (Nakaune et al. 1998). Furthermore, resistance of laboratory mutants of $B$. cinerea to azole fungicides (Ziogas and Girgis 1993) correlated with decreased accumulation of these compounds as a result of energy-dependent efflux (Stehmann and De Waard 1995). Recently, field isolates exhibiting cross resistance to different fungicides accompanied by active efflux have been reported in France (Chapeland et al. 1999). These data confirm that $\mathrm{ABC}$ transporters might play a role in protection of $B$. cinerea to fungitoxic compounds.

This paper focuses on the function of $\mathrm{ABC}$ transporters from $B$. cinerea in plant pathogenesis and protection against fungicides. We cloned and characterized the $A B C$ transporter encoding gene BcatrB. Replacement of the BcatrB gene resulted in increased sensitivity to the grapevine phytoalexin resveratrol and a slight reduction in virulence on grapevine leaves. Additionally, increased sensitivity to the phenylpyrrole fungicide fenpiclonil was observed. Hence, we have shown that BcatrB may be a virulence factor of $B$. cinerea, which also can play a role in sensitivity to commercial fungicides.

\section{RESULTS}

\section{Cloning of genes encoding ABC transporters.}

Screening of a genomic library of $B$. cinerea in $\lambda$-EMBL3 with a $1.5-\mathrm{kb} B g l \mathrm{II}-\mathrm{Taq} \mathrm{I}$ fragment from the yeast ABC transporter PDR5 yielded several hybridizing clones. Sequence analysis of two phages revealed open reading frames (ORFs) with homology to PDR5. The corresponding genes were assigned the names BcatrA and BcatrB (B. cinerea ATP-binding transporter $\mathrm{A}$ and $\mathrm{B}$, respectively). Southern analysis with gene-specific probes derived from the less-conserved regions of BcatrA and BcatrB demonstrated that they are single-copy genes that do not cross hybridize. This paper describes the characterization and functional analysis of BcatrB. BcatrA will be described in a separate paper.

A 5-kb EcoRV fragment and an overlapping 5.5-kb SalI fragment were subcloned in pBluescript, a restriction map was constructed, and the sequence was determined (Fig. 1). Assembly of sequences revealed a 4.3-kb ORF in which the presence of one intron was suggested on the basis of a sequence comparison. The presence of a 56-bp intron at position 1,116 to 1,171 was confirmed by reverse transcriptionpolymerase chain reaction (RT-PCR). The 5 '-flanking region (833 bp) of BcatrB contains a conserved Kozak sequence (CCAUCAUGG) around the deduced translation start (Kozak 1984) and a TATA box (Chen and Struhl 1988) at position -220 . In addition to these general promoter features, a single putative Pdr1p/Pdr3p binding element (Katzmann et al. 1996) is present at position -555 , and a Ste11 and a Mat1-Mc binding site at position -165 (Kjaerulff et al. 1997). In yeast, these elements are involved in regulation of expression of $\mathrm{ABC}$ transporters involved in MDR and mating. No polyadenylation signal consensus sequence (AATAAA) in the $3^{\prime}-$ flanking region was found.

BcatrB encodes a 1,439 amino acid protein with homology to $A B C$ transporters of other fungi (Del Sorbo et al. 2000) such as PDR5 and SNQ2 from S. cerevisiae and AtrA and AtrB from A. nidulans (Table 1). The degree of homology between BcatrB and AtrB from A. nidulans is particularly high (67.5\% identity). Alignment of the conserved amino acid stretches in the $\mathrm{N}$ - and $\mathrm{C}$-terminal NBFs of the proteins (Table 2) demonstrates that the NBFs in both halves are highly conserved in BcatrB and $\mathrm{ABC}$ transporters from other fungi and yeasts. The conserved sequence stretches in fungal $\mathrm{ABC}$ transporters are longer than the general consensus described for other organisms (Higgins 1992; Walker et al. 1982). Characteristics of fungal $\mathrm{ABC}$ transporters such as a degenerated Walker motif in the C-terminal NBF and the presence of a cysteine instead of a lysine residue in the $\mathrm{N}$-terminal Walker A motif also are found in BcatrB. Prediction of transmembrane helices of BcatrB with the prediction of transmembrane regions and orientation (Tmpred) routine of the EMBL server (Hofmann 1993) yields a pattern that strongly resembles that of PDR5 and AtrB. The protein consists of four domains, two hydrophobic $\mathrm{TM}_{6} \mathrm{~s}$ and two hydrophilic NBFs organized in a $\left[\mathrm{NBF}-\mathrm{TM}_{6}\right]_{2}$ topology.

\section{Expression of BcatrB in vitro.}

Northern blot analysis showed that BcatrB has a low level of basal expression in germlings grown in liquid-shake culture. Transcription of BcatrB is induced specifically by the phytoalexins resveratrol (50 mg per liter) and pisatin $(20 \mathrm{mg}$ per liter) from grapevine and pea, respectively, and the phenylpyrrole fungicide fenpiclonil (10 mg per liter) (Fig. 2). The fungicide tebuconazole (10 mg per liter) (Fig. 2) and the antibiotic cycloheximide (50 mg per liter; data not shown) give only weak induction. Transcript levels of actin in lanes 4, 5, and 9 (Fig. 2) are relatively low. This may be because the treatment of germlings with fenpiclonil and pisatin has a strong fungitoxic effect. The basal expression level of BcatrB in the azole-resistant isolate G25 and the benzimidazoleresistant isolate SAS405 did not differ significantly from the sensitive strains B3 and B05.10 (results not shown).

\section{Replacement of BcatrB.}

Functional analysis of BcatrB was studied in gene replacement mutants obtained with the construct pBABOHT in which a 2.6-kb XbaI-SalI fragment of the BcatrB se- 
quence is replaced by a $2.7-\mathrm{kb}$ hygromycin resistance cassette (OHT) (Fig. 1). Transformation of the haploid B. cinerea strain B05.10 with pBABOHT yielded approximately 60 hygromycin-resistant colonies. Homokaryotic transformants were purified by three rounds of monospore isolation and alternating growth on selective and nonselective media. To verify the replacement of the BcatrB gene, DNA from the transformants was subjected to digestion with HindIII, Southern blotted, and hybridized with the $3.5-\mathrm{kb}$ SalIEcoRV probe (Fig. 1). Restriction of DNA from strains with a wild-type copy of BcatrB with HindIII results in three fragments containing BcatrB sequences: a $2.8-\mathrm{kb}$ fragment from the $5^{\prime}$ side with flanking region, a $0.7-\mathrm{kb}$ internal fragment, and a 7-kb fragment from the $3^{\prime}$ side with flanking region. Restriction with HindIII of DNA from mutants with $B$ catrB replaced by a double crossover would result in two fragments containing BcatrB sequences, each approximately $5.2 \mathrm{~kb}$ long, without an internal fragment. Genome analysis of transformants revealed three major types of integration events: ectopic integrations, heterokaryons in which only a fraction of all nuclei contained the mutant copy, and homokaryons, in which all nuclei contained the mutant copy (Fig. $3)$. From type 3 , two independent transformants were selected: $\triangle \mathrm{B}$ catrB 4 and $\Delta \mathrm{BcatrB} 5$. Northern analysis of both mutants confirmed that wild-type mRNA of BcatrB was not present, not even after treatment with resveratrol or fenpiclonil at concentrations that induce elevated transcript levels in wild-type strains (Fig. 4). The absence of BcatrB in the replacement mutant strains was confirmed in three independent Northern analysis experiments.

\section{Sensitivity to toxicants.}

Vegetative growth of the mutants $\Delta \mathrm{BcatrB} 4$ and $\Delta \mathrm{Bcatr} B 5$ on solid media (PDA, MEA, $1 \times$ Gamborg's B5) is similar to that of the wild-type strain B05.10 (data not shown). No difference in growth rate or timing and production of conidia was observed. In radial growth tests, the mutants showed increased sensitivity to the stilbene phytoalexin resveratrol when compared with the parental strain B05.10 (Table 3). All strains showed the characteristic brown discoloration associated with resveratrol conversion by laccase activity. No difference in sensitivity to the isoflavonoid phytoalexin pisatin from Pisum sativum was observed. The $\Delta$ BcatrB mutants did not show increased sensitivity to the antibiotic cycloheximide, the dicarboximide fungicide vinclozolin, and the azole fungicide imazalil. The $\Delta \mathrm{BcatrB}$ mutants exhibited a small but significant increase in sensitivity to the phenylpyrrole fungicide fenpiclonil (Table 3). The increase in sensitivity was found for spore germination, germ-tube elongation (Fig. 5A), and colony formation (Fig. 5B), yet was hardly detectable for mycelial growth (Fig. 6). The increase in sensitivity of $\Delta \mathrm{B}$ catrB mutant spores is most apparent at concentrations of fenpiclonil of 0.05 to $0.1 \mathrm{mg}$ per liter.

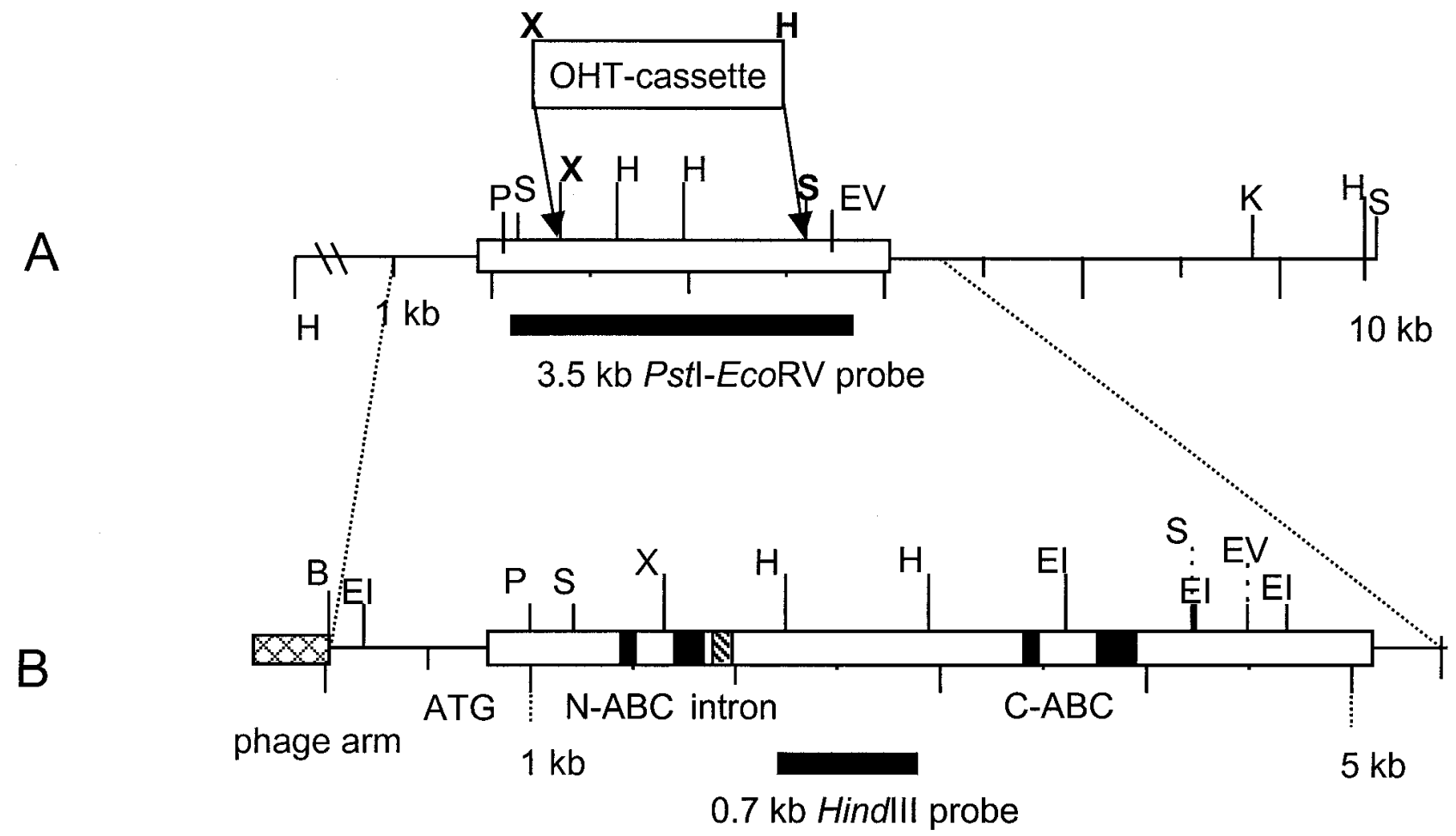

Fig. 1. Physical map of the BcatrB locus from Botrytis cinerea in A, genomic DNA and $\mathbf{B}$, a phage clone. The conserved regions encoding the Walker A motif, ATP-binding cassette signature, and Walker B motif in the $5^{\prime}$ and $3^{\prime}$ halves of the open reading frame are indicated by black boxes. B, The intron is indicated by a shaded box. B = BstXI; EI = EcoRI; EV = EcoRV; H = HindIII; S = SalI; P = PstI; and X = XbaI. Sites used for construction of the disruption construct are in bold. Arrows indicate replacement of a 2.6-kb XbaI-SalI fragment by the hygromycin resistance cassette (2.7-kb XbaIHindIII fragment) in the $\Delta B$ catrB mutants. Black bars indicate the probes used for hybridization. The 0.7-kb HindIII fragment was used as a genespecific probe in Northern and Southern blotting. The 3.5-kb PstI-EcoRV fragment was used as a probe in Southern blotting to determine genomic organization in the transformants. 
Virulence assays.

Virulence of the $\Delta \mathrm{BcatrB}$ mutants was tested in wet chambers on detached grapevine leaves at $4^{\circ} \mathrm{C}$ (Table 4). The size of lesions caused by the control transformant T132 was not significantly different from the parental strain (exp. 1 and 2). In two independent experiments (exp. 2 and 3), the spreading necrotic lesions caused by mutants $\Delta \mathrm{BcatrB} 4$ and $\Delta \mathrm{BcatrB} 5$ were significantly smaller ( $\mathrm{P}<0.05$ in Student's $t$ test) than those formed by the parental strain B05.10. In experiment 3, the determined growth rate of the mutants $\triangle \mathrm{BcatrB} 4(1.1 \pm$ $0.9 \mathrm{~mm}$ per day) and $\Delta$ BcatrB5 $(1.1 \pm 1.1 \mathrm{~mm}$ per day $)$ also was significantly lower than that of B05.10 (2.2 $\pm 1.2 \mathrm{~mm}$ per day).

\section{DISCUSSION}

The ABC transporter BcatrB from $B$. cinerea has high homology with $\mathrm{ABC}$ transporters from other fungi (Del Sorbo et al. 2000) such as the PDR proteins PDR5 and SNQ2 from $S$. cerevisiae (Balzi and Goffeau 1995), AtrB from A. nidulans (Del Sorbo et al. 1997), Pmr1 from P. digitatum (Nakaune et al. 1998), and Abc1 from M. grisea (Urban et al. 1999). This suggests a similar role for BcatrB in protection against exoge- nous toxic compounds or in plant pathogenesis. Indeed, our study shows that BcatrB is involved in protection against the grapevine phytoalexin resveratrol and the phenylpyrrole fungicide fenpiclonil. The finding that BcatrB protects against resveratrol is significant because it is known that susceptibility of grapevine to $B$. cinerea is inversely correlated with the resveratrol contents of the grapevine cultivar (Jeandet et al. 1995). The hypothesis that BcatrB can contribute to the virulence of $B$. cinerea on plants producing resveratrol was confirmed on grapevine leaves on which $\Delta B$ catrB mutants showed slightly reduced virulence. Because virulence is not fully lost, we propose that BcatrB is one of the many factors that contribute to virulence. Recently, it has been described that $\mathrm{Abc1}$, an $\mathrm{ABC}$ transporter homolog from the rice blast fungus $M$. grisea, is important for virulence on rice (Urban et al. 1999). The interaction between rice and M. grisea is accompanied by production of phytoalexins in the host (Kodama et al. 1992). Increased sensitivity to these plant defense compounds may explain the loss of virulence of $A B C 1$ mutants. Mutants do not show increased sensitivity to a number of phytoalexins in vitro, however, despite the ability of these compounds to induce expression of $\mathrm{ABC} 1$ in the wild type. Therefore, an explanation for the loss of virulence in the

Table 1. Homology of ATP-binding cassette transporters ${ }^{\mathrm{a}}$

\begin{tabular}{|c|c|c|c|c|c|c|c|c|c|c|}
\hline Source & Accession no. & Protein & BcatrA & AtrB & $\operatorname{Atr} A$ & Pdr5p & Snq2p & Cdr1p & Abc1 & PMR1 \\
\hline $\mathrm{Bc}$ & AJ006217 & BcatrB & 36.5 & 67.5 & 32.7 & 31.3 & 33.3 & 32.3 & 33.1 & 32.2 \\
\hline $\mathrm{Bc}$ & Z68906 & BcatrA & $* * *$ & 36.0 & 30.8 & 31.3 & 31.0 & 29.9 & 30.4 & 30.8 \\
\hline An & Z68905 & AtrB & & $* * *$ & 31.6 & 32.6 & 32.5 & 31.5 & 31.6 & 32.0 \\
\hline An & Z68904 & AtrA & & & $* * *$ & 41.4 & 37.8 & 41.5 & 42.0 & 42.4 \\
\hline $\mathrm{Sc}$ & L19922 & $\operatorname{Pdr} 5 p$ & & & & $* * *$ & 35.9 & 53.6 & 43.3 & 45.5 \\
\hline $\mathrm{Sc}$ & X66732 & Snq2p & & & & & $* * *$ & 36.5 & 33.9 & 35.8 \\
\hline $\mathrm{Ca}$ & X77589 & Cdr1p & & & & & & $* * *$ & 44.4 & 48.2 \\
\hline $\mathrm{Mg}$ & AF032443 & $\mathrm{Abc1}$ & & & & & & & $* * *$ & 57.1 \\
\hline $\mathrm{Pd}$ & AB010442 & PMR1 & & & & & & & & $* * *$ \\
\hline
\end{tabular}

${ }^{a}$ Botrytis cinerea $(\mathrm{Bc})$, Aspergillus nidulans $(\mathrm{An})$, Saccharomyces cerevisiae $(\mathrm{Sc})$, Candida albicans $(\mathrm{Ca})$, Magnaporthe grisea $(\mathrm{Mg})$, and Penicillium digitatum $(\mathrm{Pd})$ expressed as percentage identical amino acids.

Table 2. Alignment of the ATP-binding domain of BcatrB with homologous sequences in ATP-binding cassette (ABC) transporters ${ }^{\mathrm{a}}$

\begin{tabular}{|c|c|c|c|c|}
\hline Protein & Source & Walker A & ABC signature & Walker B \\
\hline $\mathrm{N}$ terminal & & GxSGXGKS $^{b}$ & SGGQ & LXXDEXXSALD \\
\hline BcatrB & $\mathrm{Bc}^{\mathrm{c}}$ & LLVLGRPGAGCTTLLK & \multicolumn{2}{|c|}{ GVSGGERKRVSIIEMLASRGSVMCWDNSTRGLD } \\
\hline BcatrA & $\mathrm{Bc}$ & LLVLGRPGSGCSTFLK & \multicolumn{2}{|c|}{ GVSGGERKRVSIAETLPTKKTVVSWDNSTRGLD } \\
\hline AtrB & An & LLVLGRPGSGCTTLLK & \multicolumn{2}{|c|}{ GVSGGERKRVSIIECLGTRASVFCWDNSTRGLD } \\
\hline AtrA & An & LLVLGRPGTGCSTFLK & \multicolumn{2}{|c|}{ GVSGGERKRVSIAEMALAMTPFAAWDNSSRGLD } \\
\hline PDR5 & $\mathrm{Sc}$ & LVVLGRPGSGCTTLLK & \multicolumn{2}{|c|}{ GVSGGERKRVSIAEVSICGSKFQCWDNATRGLD } \\
\hline SNQ2 & $\mathrm{Sc}$ & ILVLGRPGAGCSSFLK & \multicolumn{2}{|c|}{ GVSGGERKRVSIAEALAAKGSIYYCWDNATRGLD } \\
\hline CDR1 & $\mathrm{Ca}$ & TVVLGRPGAGCSTLLK & \multicolumn{2}{|c|}{ GVSGGERGRVDIAEASLSGANIQCWDNATRGLD } \\
\hline Abc1 & $\mathrm{Mg}$ & LVVLGPPGSGCSTFLK & \multicolumn{2}{|c|}{ GVSGGERKRVTIAEAALSGAPLQCWDNSTRGLD } \\
\hline PMR1 & $\mathrm{Pd}$ & LIVLGPPGSGCSTFLK & \multicolumn{2}{|c|}{ GVSGGERKRVSIAEATLCGSPLQCWDNSTRGLD } \\
\hline $\mathrm{C}$ terminal & & GxSGxGKS ${ }^{\mathrm{b}}$ & SGGQ & LXXDEXXSALD \\
\hline BcatrB & $\mathrm{Bc}$ & LGALMGSSGAGKTTLL & \multicolumn{2}{|c|}{ LSVEQRKRLTIGVELVSKPSILIFLDEPTSGLD } \\
\hline BcatrA & $\mathrm{Bc}$ & MVALMGASGAGKTTLL & \multicolumn{2}{|c|}{ LSVEQRKRVTIGVELAAKPNLLLFLDEATSGLD } \\
\hline AtrB & An & LGALMGSSGAGKTTLL & \multicolumn{2}{|c|}{ LSVEQRKRVTIGVELVSKPSILIFLDEPTSGLD } \\
\hline AtrA & An & LTALMGVSGAGKTTLL & \multicolumn{2}{|c|}{ LNVEQRKLLTIGVELPPSPKLLLFLDEPTSGLD } \\
\hline PDR5 & $\mathrm{Sc}$ & LTALMGASGAGKTTLL & \multicolumn{2}{|c|}{ LNVEQRKRLTIGVELTAKPKLLVFLDEPTSGLD } \\
\hline SNQ2 & $\mathrm{Sc}$ & MTALMGESGAGKTTLL & \multicolumn{2}{|c|}{ LNVEQRKKLSIGVELVAKPDLLLFLDEPTSGLD } \\
\hline CDR1 & Ac & ITALMGASGAGKTTLL & \multicolumn{2}{|c|}{ LNVEQRKRLTIGVELVAKPKLLLFLDEPTSGLD } \\
\hline Abc1 & $\mathrm{Mg}$ & LTALMGVSGAGKTTLL & \multicolumn{2}{|c|}{ LNVEQRRRLTIGVELAAKPPLLLFVDEPTSGLD } \\
\hline Pmr1 & Pd & CTALMGVSGAGKTTLL & \multicolumn{2}{|c|}{ LNVEQRKRLTIGVELAAKPQLLLFLDEPTSGLD } \\
\hline
\end{tabular}

\footnotetext{
${ }^{a}$ Identical sequences in fungal ABC-transporters in bold.

${ }^{\mathrm{b}}$ General consensus sequence of ABC transporters (Higgins 1992; Walker et al. 1982).

c Botrytis cinerea $(\mathrm{Bc})$, Aspergillus nidulans $(\mathrm{An})$, Saccharomyces cerevisiae $(\mathrm{Sc})$, Candida albicans $(\mathrm{Ca})$, Magnaporthe grisea $(\mathrm{Mg})$, and Penicillium digitatum $(\mathrm{Pd})$.
} 
$A B C 1$ mutants of $M$. grisea is not yet known. It may be that Abc1 provides protection against a yet-unidentified phytoalexin. Similar mechanisms may be involved in the protection of other plant pathogens against phytoalexins. For instance, activity of $\mathrm{ABC}$ transporters could explain the nondegradative tolerance of pisatin, a phytoalexin from P. sativum, in Nectria haematococca on the basis of energy-dependent efflux (Denny et al. 1987).

Although pisatin induces higher transcript levels of BcatrB in the wild-type isolate of $B$. cinerea, the $\Delta$ BcatrB mutants have the same sensitivity to pisatin as the parental isolate. The fungus may cope with this phytoalexin by means of additional transporters or degradative enzymes, as described for other pathogens such as pisatin demethylase (Schafer et al. 1989). Enzymatic degradation of resveratrol by $B$. cinerea can be accomplished by laccase-like activity (Sbaghi et al. 1996), which explains why the increased sensitivity of $\Delta \mathrm{BcatrB}$ mutants to resveratrol is moderate. We propose that BcatrB serves as a "first-aid" response to provide immediate protection against resveratrol and bridges the time required for breakdown of resveratrol by laccase activity, which was observed in the parental strain B05.10 and the $\Delta$ BcatrB mutants.

For several $\mathrm{ABC}$ transporter genes, a phenotype of single gene replacements becomes manifest only in fungicideresistant strains in which the $\mathrm{ABC}$-transporter gene responsi-

Table 3. Effect of plant defense compounds and fungicides on radial growth of Botrytis cinerea on PDA medium

\begin{tabular}{lccc}
\hline & \multicolumn{3}{c}{ Strains } \\
\cline { 2 - 4 } Compounds & B05.10 $^{\mathbf{a}}$ & $\Delta$ BcatrB4 $^{\mathbf{b}}$ & $\Delta$ BcatrB5 $^{\mathbf{b}}$ \\
\hline Pisatin & $2.1 \pm 0.5^{\mathrm{c}}$ & $2.5 \pm 0.8$ & $2 \pm 0.6$ \\
Resveratrol & $911 \pm 383^{\mathrm{c}}$ & $290 \pm 69^{\mathrm{d}}$ & $248 \pm 53^{\mathrm{d}}$ \\
Cycloheximide & $2.2 \pm 0.3^{\mathrm{c}}$ & $1.9 \pm 0.6$ & $1.8 \pm 0.1$ \\
Fenpiclonil & $12 \pm 5^{\mathrm{e}}$ & $8.8 \pm 2^{\mathrm{d}}$ & $7.7 \pm 2^{\mathrm{d}}$ \\
Vinclozolin & $80 \pm 20^{\mathrm{e}}$ & $70 \pm 20$ & $80.0 \pm 10$ \\
\hline
\end{tabular}

a Wild-type parental isolate.

${ }^{\mathrm{b}}$ BcatrB gene-replacement mutants.

c $50 \%$ effective concentration (milligrams per liter) \pm experimental error.

${ }^{\mathrm{d}}$ Significantly different from B05.10 $(\mathrm{P}<0.05)$.

e $50 \%$ effective concentration (micrograms per liter) \pm experimental error.

\section{$\begin{array}{lllllllll}1 & 2 & 3 & 4 & 5 & 6 & 7 & 8 & 9\end{array}$}

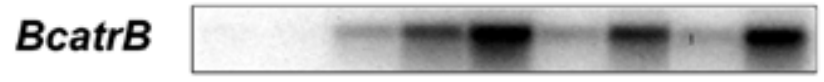

\section{BcactA}

\section{rRNA}

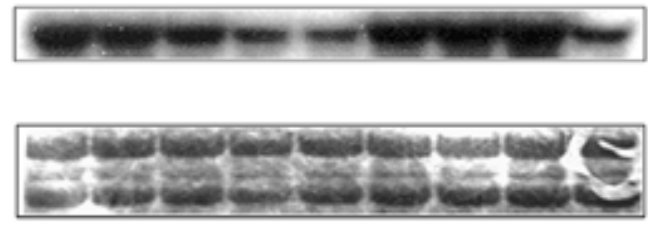

Fig. 2. Expression of BcatrB in Northern blot experiments. RNA was hybridized with the 0.7-kb HindIII fragment of BcatrB (Fig. 1). Transcript levels of BcatrB in germlings of strain B05.10 after 60 min of mock-treatment (lane 1) or treatment with $0.1 \%$ methanol (lane 2), fenpiclonil (1, 3, and $10 \mathrm{mg}$ per liter; lanes 3, 4, and 5), resveratrol (20 and $50 \mathrm{mg}$ per liter; lanes 6 and 7), tebuconazole (10 mg per liter; lane 8), and pisatin (25 mg per liter; lane 9). BcactA shows hybridization with the Botrytis cinerea actin gene. rRNA shows methylene blue staining of ribosomal RNA. ble for resistance is overexpressed. In $P$. digitatum disruption of the PMR1 gene in the azole-resistant strain LC2, which overexpresses PMR1, sensitivity to azole fungicides is restored to wild-type levels but not beyond those levels (Nakaune et al. 1998). The observation that replacement of $B$ catrB in a wild-type strain results in increased sensitivity to resveratrol and fenpiclonil indicates that BcatrB has a relatively high activity toward these compounds. Because the fungicide fenpiclonil is derived from the antibiotic pyrrolnitrin, the activity of BcatrB toward fenpiclonil may relate to the fact that $B$. cinerea needs to protect itself against natural toxins during saprophytic growth (Atlas and Bartha 1993). Among these are antibiotics such as pyrrolnitrin produced by Pseudomonas spp. (Ligon et al. 2000). It is possible that BcatrB is involved in protection against pyrrolnitrin, as shown for the structurally related fenpiclonil. If $\mathrm{ABC}$ transporters provide protection against natural toxicants, they could be significant in determining the broad host range and the saprophytic ability of $B$. cinerea.

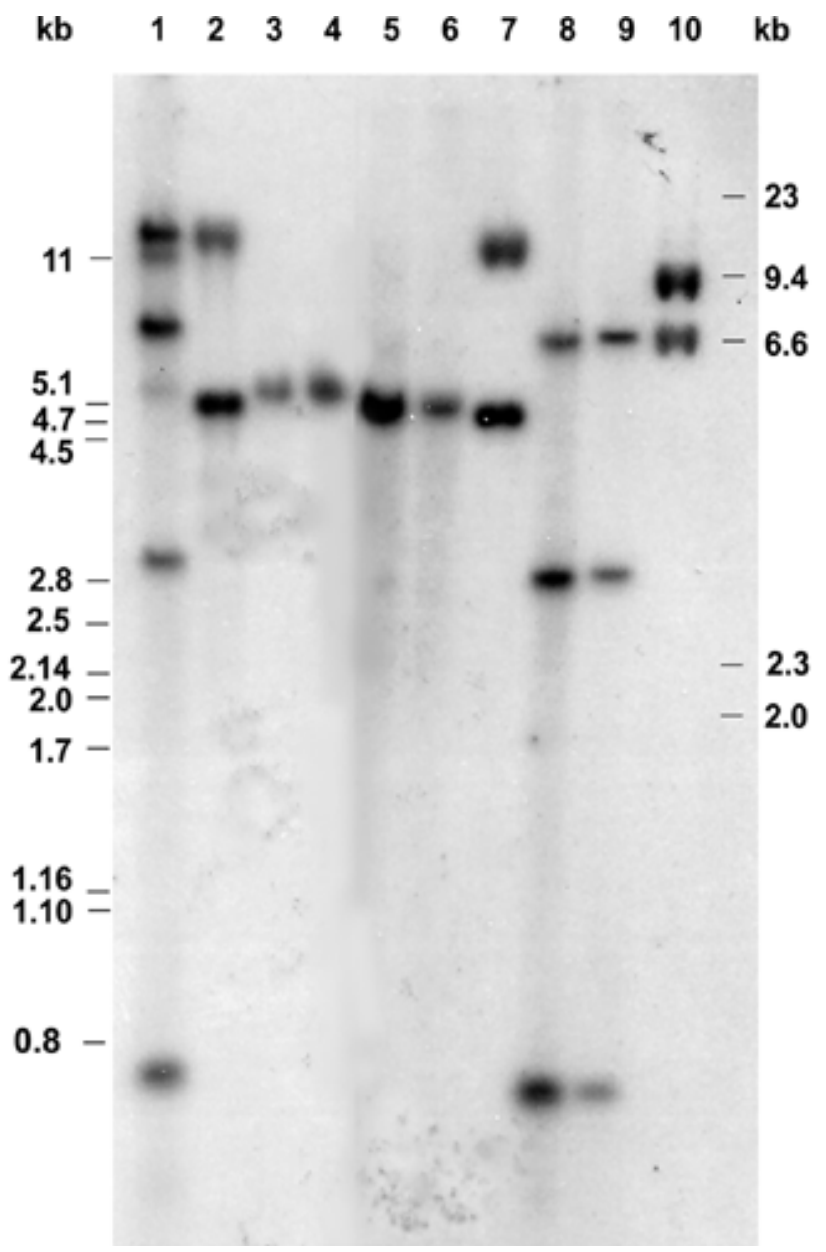

Fig. 3. Southern blot with DNA from Botrytis cinerea strains SAS56 and B05.10 (wild type) and five putative $\Delta$ BcatrB mutants obtained by transformation with the construct pBABOHT. DNA was digested with HindIII and hybridized with a 3.5-kb Pst I-EcoRV probe from BcatrB (Fig. 1). Heterokaryotic transformant (lane 1), $\lambda$ PstI marker (lane 2), homokaryotic transformants $\Delta \mathrm{BcatrB} 4,5,15$ and 45 (lanes $3,4,5$ and 6 , respectively.), $\lambda$ PstI marker (lane 7), parental isolate B05.10 (lane 8), wild-type isolate SAS56 (lane 9), and $\lambda$ HindIII marker (lane 10). Molecular size markers $(\mathrm{kb})$ are indicated. 
Transcription of BcatrB can be induced by fungitoxic compounds (resveratrol and cycloheximide) that also induce transcription of $\mathrm{ABC}$ transporter genes in other fungi (Del Sorbo et al. 1997; Miyahara et al. 1995). In fact, overlapping sets of compounds can induce several ABC transporters in $S$. cerevisiae and Candida albicans. In S. cerevisiae, the induction of PDR5, SNQ2, and YOR1 is regulated by the transcription factors Pdr1p and Pdr3p (Mahé et al. 1996). The promoters of transporter genes in the PDR network all contain one or more PDR elements (TCCG(C/T)GGAA) (Katzmann et al. 1994). Binding of Pdr1p or Pdr3p to these boxes stimulates expression of these genes (Katzmann et al. 1996). Modification of Pdr1p, Pdr3p, or the PDR elements leads to changes in expression of the PDR genes (Hallstrom and Moye-Rowley 1998), thereby altering the sensitivity to toxic compounds. The promoter of BcatrB contains a sequence stretch (TCCACGGAA, $551 \mathrm{bp}$ upstream of the start codon) that strongly resembles the yeast PDR elements. Although no PDR1 or PDR3 homolog is known in B. cinerea to date, the presence of this box suggests that regulation of ABC transporters in B. cinerea may be similar to that in $S$. cerevisiae. Cycloheximide and pisatin induce expression of BcatrB but do not have an increased activity toward the $\Delta B$ catrB mutants. This implies that inducers of transcription are not necessarily a substrate of that particular transporter. Furthermore, these compounds can be a substrate of other $\mathrm{ABC}$ transporters, which may be up regulated in $\triangle \mathrm{Bcatr} B$ mutants and mask the loss of BcatrB. Recently, the presence of at least 12 other $\mathrm{ABC}$ transporters has been demonstrated in an EST library of B. cinerea (F. Bitton, C. Levis, D. Fortini, J. M. Pradier, Y. Brygoo, and Genoscope-Centre National de Séquençage, unpublished). The $B$. cinerea strain T4 cDNA library was made under conditions of nitrogen deprivation (EMBL accession no. AL110624 to AL117185). This situation resembles the functioning of the PDR network in S. cerevisiae (Balzi and Goffeau 1995) and the CDR gene family in C. albicans (Sanglard et al. 1997). There, concerted action of ABC transporters with overlapping substrate specificity provides the cell with a protection system against various toxic compounds (Carvajal et al. 1997; Kolaczkowski et al. 1998). For instance, C. albicans strains resistant to azole antimycotic drugs overexpress $C D R 1, C D R 2$, or both genes (Sanglard et al. 1997). Disruption of $C D R 1$ results in an increased sensitivity to azole drugs that can be overcome by overexpression of CDR2. Disruption of $C D R 2$ increased sensitivity to azoles only in an azole-resistant $\triangle C D R 1$ strain that overexpresses $C D R 2$ and not in $\triangle C D R 1$ strains with wild-type sensitivity. This illustrates that, in many instances, increased sensitivity to toxicants can only be observed in multiple knockout mutants.

In laboratory-generated mutants of $B$. cinerea, resistance to azole fungicides has been attributed to increased energydependent efflux of these compounds (Stehmann and De Waard 1995). A similar mechanism has been described for resistant field isolates (Leroux et al. 1998). This increased efflux can be explained by enhanced activity of an ABC transporter. Resistance to azole fungicides accompanied by increased expression of a particular $\mathrm{ABC}$ transporter gene has previously been described in A. nidulans (Andrade et al. 2000) and $P$. digitatum (Nakaune et al. 1998). The azole-resistant laboratory mutants of $B$. cinerea tested in our studies, however, show the same low basal expression level of BcatrB as the parental strain. Treatment of these mutants with azoles gives a similar increase of BcatrB expression in mutants and

Table 4. Virulence of Botrytis cinerea on detached grapevine leaves at $4^{\circ} \mathrm{C}$

\begin{tabular}{lcrrr}
\hline & \multicolumn{4}{c}{ Strain $^{\mathbf{y}}$} \\
\cline { 2 - 5 } Experiment & $\mathbf{B 0 5 . 1 0}$ & $\mathbf{T 1 3 2}$ & $\Delta$ BcatrB4 & $\Delta$ BcatrB5 \\
\hline 1 & $13.2 \pm 2.9 \mathrm{a}$ & $12.7 \pm 3.3 \mathrm{a}$ & & \\
2 & $8.4 \pm 2.2 \mathrm{a}^{\mathrm{z}}$ & $8.6 \pm 3.8 \mathrm{a}$ & $5.9 \pm 2.3 \mathrm{~b}$ & $6.0 \pm 1.5 \mathrm{~b}$ \\
3 & $5.7 \pm 2.0 \mathrm{a}$ & & $3.6 \pm 1.6 \mathrm{~b}$ & $4.0 \pm 1.6 \mathrm{~b}$ \\
\hline
\end{tabular}

${ }^{\mathrm{y}}$ B05.10 (parental wild-type strain), T132 (B05.10 transformed with hygromycin resistance cassette), and $\Delta \mathrm{B}$ catrB 4 and $\Delta \mathrm{BcatrB} 5$ (BcatrB gene-replacement mutants).

${ }^{\mathrm{z}}$ Average lesion size (diameter in millimeters). Values within one row followed by the same letter do not differ significantly $(P<0.05$; student's $t$ test).

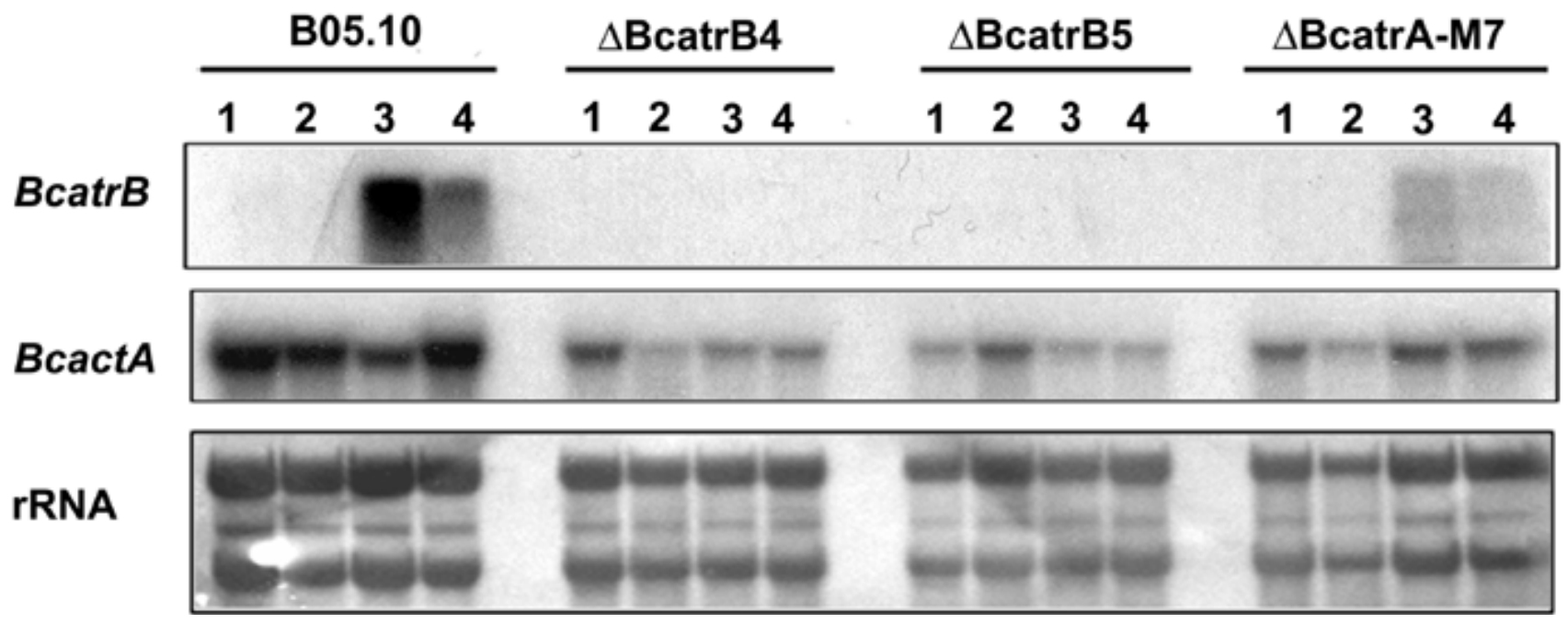

Fig. 4. Expression of BcatrB in Northern blot experiments. RNA was hybridized with the 0.7-kb HindIII fragment of BcatrB. Transcript levels of BcatrB in parental strain B05.10, gene replacement mutants $\triangle \mathrm{B}$ catrB4 and $\Delta \mathrm{B}$ catrB5, and control strain $\Delta \mathrm{B}$ catrA-M7 are indicated. Germlings were mock treated (lanes 1), treated with methanol (0.1\%; lanes 2), fenpiclonil (10 mg per liter; lane 3), or resveratrol (50 mg per liter; lane 4). BcactA shows hybridization with the Botrytis cinerea actin gene. rRNA shows methylene blue staining of ribosomal RNA. 
wild type. These results indicate that a yet-unidentified transporter is involved in resistance to azole fungicides.

In conclusion, our results suggest a mutual role for BcatrB from $B$. cinerea in protection against activity of plant defense compounds and fungicides. Further studies may elucidate the importance of BcatrB and other $\mathrm{ABC}$ transporters as virulence factors of the fungus on additional host plants and as protection against a wider variety of toxic compounds.

\section{MATERIALS AND METHODS}

\section{Culturing of fungal strains.}

Strain SAS56, a monoascospore isolate (Van der VlugtBergmans et al. 1993) and the haploid strain B05.10 derived from SAS56 (a gift from P. Büttner and P. Tudzynski, Institut für Botanik, Westfälische Wilhelms-Universität, Münster, Germany) were used as reference strains. T132 is a hygromycin-resistant strain derived from $\mathrm{B} 05.10$ by transformation with the plasmid pOHT containing the hygromycin resistance cassette OHT (Van Kan et al. 1997). $\triangle$ BcatrA-M7 is a genereplacement mutant derived from B05.10 in which BcatrA is replaced by the OHT cassette (Del Sorbo, unpublished).

The monoascospore strain SAS405, provided by F. Faretra (University of Bari, Italy), contains the alleles $\mathrm{MbclHr}$ and DaflLR, which confer resistance to benzimidazoles and dicarboximides, respectively (Faretra and Pollastro 1991).

Isolate B3 is an azole-sensitive strain isolated from tomato in Greece. The monospore isolate G25 is a laboratorygenerated mutant derived from B3 with reduced sensitivity to azole fungicides (Stehmann and De Waard 1996), provided by B. N. Ziogas (University of Athens, Greece).

All strains were cultured at $20^{\circ} \mathrm{C}$ in the dark on tPDA (potato dextrose agar amended with $300 \mathrm{~g}$ of homogenized tomato leaves per liter). After 3 days, the cultures were exposed to near-UV light for $16 \mathrm{~h}$ and incubated for 1 additional week in the dark. Conidia were collected from sporulating cultures to inoculate liquid cultures in Gamborg's B5 medium (Duchefa Biochemie, Haarlem, The Netherlands) supple-

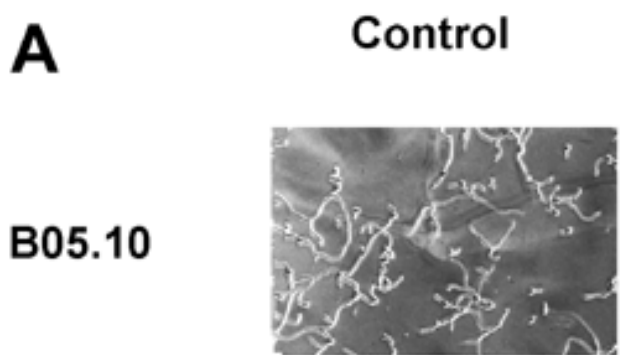

\section{Resveratrol $100 \mathrm{mg} \mathrm{l}^{-1}$}
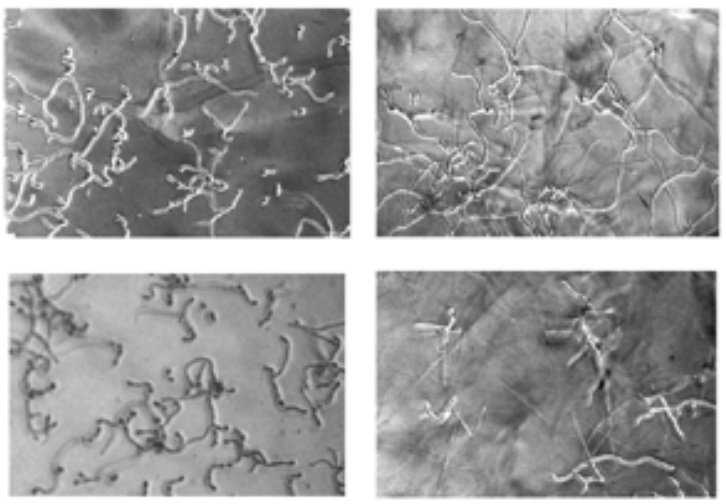

\section{$\Delta$ BcatrB4}

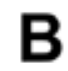

B

\section{Fenpiclonil $0.056 \mathrm{mg} \mathrm{l}^{-1}$}
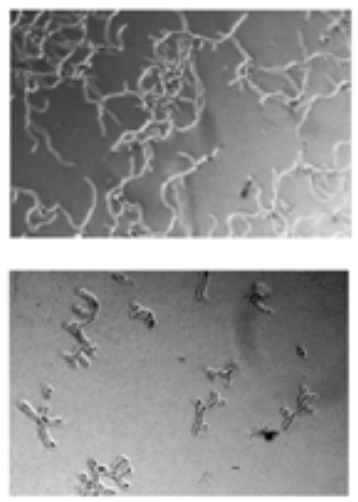

\section{Fenpiclonil} $0.1 \mathrm{mg} \mathrm{l}^{-1}$
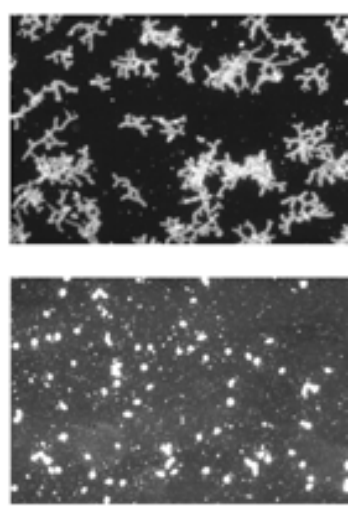

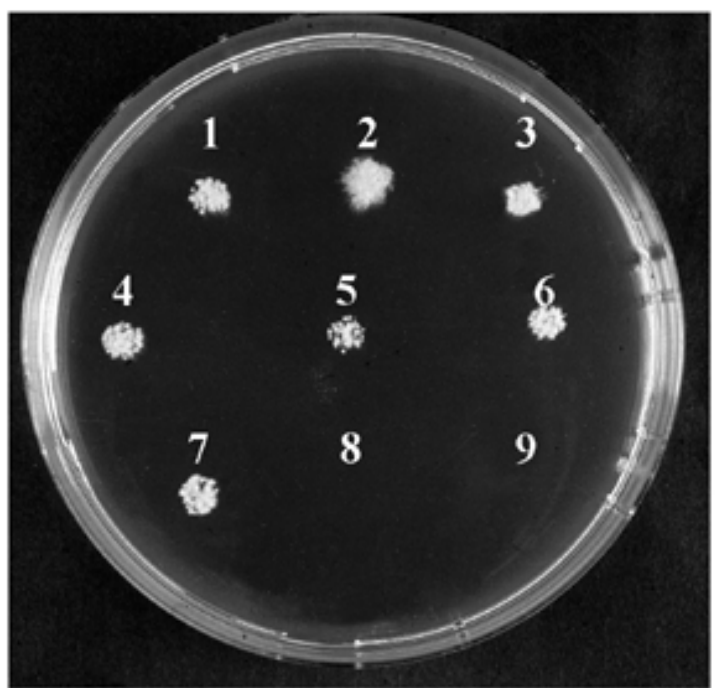

Fig. 5. Effect of resveratrol and fenpiclonil on growth of Botrytis cinerea. A, Spore germination and germ-tube growth of strains B05.10 (parental strain) and $\triangle \mathrm{B}$ catrB4 (BcatrB replacement mutant) in $\mathrm{B} 5$ medium after $22 \mathrm{~h}$ incubation at $20^{\circ} \mathrm{C}$. B, Colony formation on B5 agar amended with $0.1 \mathrm{mg}$ of fenpiclonil per liter after 1 week incubation at room temperature. Untransformed control strains (spots 1,2, and 3), $\Delta$ BcatrA mutants (spots 4, 5, and 6), T132 control (B05.10 transformed with hygromycin resistance cassette) (spot 7), and $\Delta$ BcatrB mutants (spots 8 and 9) are indicated. 
mented with $1 \%$ sucrose and $10 \mathrm{mM}$ ammonium phosphate ( $\mathrm{pH}$ 6.5). Germlings from overnight cultures were used for induction experiments and DNA and RNA isolation. Hygromycin-resistant transformants were maintained on malt extract agar (Oxoid, Basingstoke, Hampshire, England) plates amended with $100 \mathrm{mg}$ of hygromycin per liter (Sigma, St. Louis, MO, U.S.A.) and transferred to tPDA to harvest spores for experiments.

B. cinerea strain B05.10 was transformed with the use of protoplasts (Hamada et al. 1994) with modifications as described previously (Van Kan et al. 1997).

\section{Molecular techniques.}

DNA manipulations were performed according to standard methods (Sambrook et al. 1989). Escherichia coli strain DH5 $\alpha$ was used for propagation of constructs. The $\lambda$-EMBL3 system (Promega, Madison, WI, U.S.A.) was used to construct a library of $B$. cinerea strain SAS56 genomic DNA partially digested with SauIIIA.

The library was screened with a probe derived from the $S$. cerevisiae gene PDR5, provided by A. Goffeau (Louvain-laNeuve, Belgium). This 1.5-kb BglII-TaqI fragment comprises the entire N-terminal ATP-binding cassette domain of PDR5. Membranes (Hybond-N ${ }^{+}$, Amersham, Arlington Heights, IL, U.S.A.) were hybridized with random-primed (GIBCO, Gaithersburg, MD, U.S.A.), $\left[\alpha-{ }^{32} \mathrm{P}\right] \mathrm{dATP}-$ labeled probes at $56^{\circ} \mathrm{C}$ in modified Church buffer (Church and Gilbert 1984), and washed at $56^{\circ} \mathrm{C}$ in $1 \times \mathrm{SSC}$. Fragments from positive phages were subcloned in $\operatorname{pGEM} 3 Z(+)$ (Promega) or pBluescriptII-SK (Stratagene, La Jolla, CA, U.S.A.). Sequencing was performed with the Thermo Sequenase II cycle sequencing kit (Amersham Pharmacia Biotech, Uppsala, Sweden).

Genomic DNA of B. cinerea was isolated as described previously (Drenth et al. 1993), digested with restriction enzymes, fractionated on $1.0 \%$ agarose-TAE gels, and transferred to Hybond- $\mathrm{N}^{+}$membranes by capillary blotting (Sambrook et al. 1989). Blots were hybridized with randomprimed, $\left[\alpha-{ }^{32} \mathrm{P}\right] \mathrm{dATP}-$ labeled probes at $65^{\circ} \mathrm{C}$ in modified Church buffer, washed at $65^{\circ} \mathrm{C}$ in $0.2 \times \mathrm{SSC}$, and exposed to X-OMAT AR films (Kodak, Rochester, NY, U.S.A.).

\section{Gene expression.}

For RNA induction experiments, precultures were grown in $300-\mathrm{ml}$ round-bottom flasks $(100 \mathrm{ml}$ of $\mathrm{B} 5$ medium and $10^{6}$ conidia per $\mathrm{ml}$ ) at $20^{\circ} \mathrm{C}$ and $180 \mathrm{rpm}$ for 13 to $15 \mathrm{~h}$. If necessary, mycelium of different cultures was pooled. Following distribution over fresh flasks, inducing agents were added from a $1,000 \times$ concentrated stock solution in methanol. After additional incubation at $20^{\circ} \mathrm{C}$ and $180 \mathrm{rpm}$ for $1 \mathrm{~h}$, mycelium was harvested on glass-fiber filters and washed with ice-cold $10 \mathrm{mM}$ sodium phosphate $(\mathrm{pH}$ 6.5) and sterile water with a vacuum manifold (Millipore, Bedford, MA, U.S.A.).

Total RNA was extracted from mycelium frozen in liquid nitrogen with guanidine hydrochloride (Logemann et al. 1987). Samples of $10 \mu \mathrm{g}$ of RNA were denatured with glyoxal in dimethyl sulfoxide and subjected to electrophoresis on a $1.4 \%$ agarose gel in $10 \mathrm{mM}$ sodium phosphate. RNA was transferred to Hybond-N membranes by capillary blotting in 10x SSC (Sambrook et al. 1989). Northern blots were hybridized in modified Church buffer at $65^{\circ} \mathrm{C}$ with random primer $\left[\alpha-{ }^{32} \mathrm{P}\right] \mathrm{dATP}-\mathrm{labeled}$ probes. The gene-specific probes used were a 1.1-kb BamHI-EcoRI fragment of BcatrA, a 0.7$\mathrm{kb}$ HindIII fragment of BcatrB, and a 1.2-kb HindIII fragment of the constitutively expressed actin gene of $B$. cinerea.

\section{Construction of the gene-replacement vector.}

$\mathrm{pBABOHT}$ is the vector used for gene replacement of BcatrB (Fig. 1). In an 8-kb BstXI-KpnI fragment, a 2.6-kb $X b a \mathrm{I}-\mathrm{SalI}$ fragment from the coding region of BcatrB containing both $\mathrm{ABC}$ motifs was replaced by the OHT cassette from the plasmid pOHT, providing hygromycin resistance (Hilber et al. 1994) (provided by M. Ward, Genencor International, San Francisco, CA, U.S.A.). The resistance marker was inserted as a 2.7-kb $\mathrm{XbaI}-H i n \mathrm{dIII}$ fragment, retaining $0.8 \mathrm{~kb}$ of the $5^{\prime}$-flanking region and $1 \mathrm{~kb}$ of the coding region of BcatrB. We used HindIII from the multiple cloning sites and $K p n I$ to insert a $4.5-\mathrm{kb}$ fragment from the $3^{\prime}$ end of the gene. The plasmid was linearized with $K p n I$ prior to transformation to obtain double crossover integration.

\section{Toxicity assay.}

For all toxicants, $50 \%$ effective concentration values $\left(\mathrm{EC}_{50}\right)$ for inhibition of radial growth were determined on PDA and solidified B5 medium, as described previously (Stehmann and De Waard 1996). Test compounds were added in a range of concentrations from $1,000 \times$ stock solutions in methanol and resveratrol from freshly prepared 500× stock solutions. Experiments were carried out in triplicate and repeated two or three times. Student's $t$ test was used for statistical analysis.

Toxic activity of compounds in liquid B5 medium was determined in 96-well polystyrene plates (Greiner, Alphen a/d Rijn, The Netherlands). Wells were inoculated with $5 \times 10^{3}$ spores in $100 \mu \mathrm{l}$ of medium and incubated at $20^{\circ} \mathrm{C}$ for $60 \mathrm{~h}$. Growth was measured as an increase of absorbance at $405 \mathrm{~nm}$ in an EL312 microplate reader (BIO-TEK instruments, Winooski, VT, U.S.A.).

\section{Virulence assay.}

Virulence assays were performed on detached grapevine leaves placed in prewetted florist foam (Smithers-Oasis, Grünstadt, Germany) in humid chambers. Five (experiments 1 and 2) or four (experiment 3) leaves were inoculated with $2 \times$

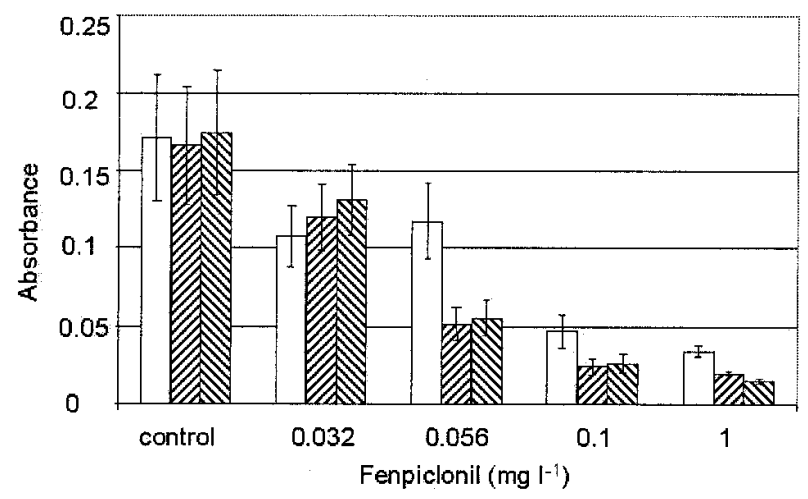

Fig. 6. Effect of fenpiclonil on germling growth of Botrytis cinerea strains B05.10 (parental strain, white), and the replacement mutants $\triangle \mathrm{BatrB} 4$ (dashed up) and $\triangle \mathrm{BatrB5}$ (dashed down) in liquid B5 medium in multiwell plates, $60 \mathrm{~h}$ incubation at $20^{\circ} \mathrm{C}$, and measured as absorbance at $405 \mathrm{~nm}$. Solvent concentrations never exceeded $0.1 \%$ methanol. 
$10^{6} \mathrm{~B}$. cinerea conidia per $\mathrm{ml}$ and preincubated in $1 \times \mathrm{B} 5 \mathrm{me}-$ dium amended with $1 \%$ sucrose and $10 \mathrm{mM}$ ammonium phosphate $(\mathrm{pH} 6.5)$ at $20^{\circ} \mathrm{C}$ for $2 \mathrm{~h}$ to synchronize germination. Four sectors were designated on the upper side of each leaf. Each sector was inoculated with 15 droplets $(1 \mu \mathrm{l})$ of strains B05.10 (parental line), T132 (control transformant), $\Delta \mathrm{BcatrB} 4$, or $\Delta \mathrm{BcatrB} 5$ (BcatrB mutants). Lesion diameters were measured after incubation at $4{ }^{\circ} \mathrm{C}$ for 6 days in experiments 1 and 2 and for 10 days in experiment 3 . Mean values of lesion sizes were determined on the basis of figures of spreading lesions (>1 mm). Student's $t$ test was used for statistical analysis. In experiment 3, the growth rate of lesions was based on measurements made on days 9,10 , and 11 .

\section{ACKNOWLEDGMENTS}

We thank J. Van Kan, A. Ten Have, and T. Prins for advice and assistance in manipulating $B$. cinerea, T. Vermeulen for help with Northern analysis experiments, and T. Van Kampen (Department of Molecular Biology, Wageningen University) for DNA sequencing. The authors appreciate the inspiring discussions with A. C. Andrade and L.-H. Zwiers, and acknowledge P. J. G. M. De Wit and B. Tyler for critical reading of the manuscript. Investigations were supported by the Council for Earth and Life Sciences (ALW), which is subsidized by The Netherlands Organisation for Scientific Research, project 805-22-462. The work G. Del Sorbo has been supported, in part, by a grant of the Consiglio Nazionale delle Ricerche (CNR), PF Biotechnolgie (contribution 99.00476 PF49) and by MURST-PRIN-COFIN1998 (contribution 9807343676-007).

\section{LITERATURE CITED}

Andrade, A. C., Del Sorbo, G., Van Nistelrooy, J. G. M., and De Waard, M. A. 2000. The ABC transporter AtrB from Aspergillus nidulans mediates resistance to all major classes of fungicides and some natural toxic compounds. Microbiology 146:1977-1985.

Atlas, R. M., and Bartha, R. 1993. Microbial Ecology: Fundamentals and Applications. 3rd ed. Benjamin/Cummings Publishing Co. Inc., Redwood City, CA, U.S.A.

Balzi, E., and Goffeau, A. 1995. Yeast multidrug resistance: The PDR network. J. Bioenerg. Biomembr. 27:71-76.

Carvajal, E., Vandenhazel, H. B., Cybularz-Kolaczkowska, A., Balzi, E., and Goffeau, A. 1997. Molecular and phenotypic characterization of yeast pdr1 mutants that show hyperactive transcription of various ABC multidrug transporter genes. Mol. Gen. Genet. 256:406-415.

Chapeland, F., Fritz, R., Lanen, C., Gredt, M., and Leroux, P. 1999. Inheritance and mechanisms of resistance to anilinopyrimidine fungicides in Botrytis cinerea (Botryotinia fuckeliana). Pestic. Biochem. Physiol. 64:85-100.

Chen, W., and Struhl, K. 1988. Saturation mutagenesis of a yeast his3 "TATA element": Genetic evidence for a specific TATA-binding protein. Proc. Natl. Acad. Sci. USA 85:2691-2695.

Church, G. M., and Gilbert, W. 1984. Genomic sequencing. Proc. Natl. Acad. Sci. USA 81:1991-1995.

De Waard, M. A. 1997. Significance of ABC transporters in fungicide sensitivity and resistance. Pestic. Sci. 51:271-275.

De Waard, M. A., and Van Nistelrooy, J. G. M. 1979. Mechanism of resistance to fenarimol in Aspergillus nidulans. Pestic. Biochem. Physiol. 10:219-229.

De Waard, M. A., and Van Nistelrooy, J. G. M. 1980. An energydependent efflux mechanism for fenarimol a fungicide in a wild-type strain and fenarimol-resistant mutants of Aspergillus nidulans. Pestic. Biochem. Physiol. 13:255-266.

Decottignies, A., and Goffeau, A. 1997. Complete inventory of the yeast ABC proteins. Nat. Genet. 15:137-145.

Del Sorbo, G., Andrade, A. C., Van Nistelrooy, J. G. M., Van Kan, J. A. L., Balzi, E., and De Waard, M. A. 1997. Multidrug resistance in Aspergillus nidulans involves novel ATP-binding cassette transporters. Mol. Gen. Genet. 254:417-426.

Del Sorbo, G., Schoonbeek, H., and De Waard, M. A. 2000. Fungal transporters involved in efflux of natural toxic compounds and fungicides. Fungal Genet. Biol. 30:1-15.

Denny, T. P., Matthews, P. S., and VanEtten, H. D. 1987. A possible mechanism of nondegradative tolerance of pisatin in Nectria haematococca MP VI. Physiol. Mol. Plant Pathol. 30:93-107.

Drenth, A., Goodwin, S. B., Fry, W. E., and Davidse, L. C. 1993. Genotypic diversity of Phytophthora infestans in the Netherlands revealed by DNA polymorphisms. Phytopathology 83:1087-1092.

Faretra, F., and Pollastro, S. 1991. Genetic basis of resistance to benzimidazole and dicarboximide fungicides in Botryotinia fuckeliana (Botrytis cinerea). Mycol. Res. 95:943-951.

Hallstrom, T. C., and Moye-Rowley, W. S. 1998. Divergent transcriptional control of multidrug resistance genes in Saccharomyces cerevisiae. J. Biol. Chem. 273:2098-2104.

Hamada, W., Reignault, P., Bompeix, G., and Boccara, M. 1994. Transformation of Botrytis cinerea with the hygromycin B resistance gene, hph. Curr. Genet. 26:251-255.

Higgins, C. F. 1992. ABC transporters: From microorganisms to man. Annu. Rev. Cell Dev. Biol. 8:67-113.

Hilber, U. W., Bodmer, M., Smith, F. D., and Koller, W. 1994. Biolistic transformation of conidia of Botryotinia fuckeliana. Curr. Genet. 25:124-127.

Hofmann, K., Stoffel, W. 1993. TMBASE: A database of membrane spanning protein segments. Biol. Chem. Hoppe-Seyler 374:166.

Ishikawa, T., Li, Z. S., Lu, Y. P., and Rea, P. A. 1997. The GS-X pump in plant, yeast, and animal cells: Structure, function, and gene expression. Biosci. Rep. 17:189-207.

Jarvis, W. R. 1977. Botryotinia and Botrytis species: Taxonomy, Physiology, and Pathogenicity: A Guide to the Literature. Vol. 15. Canada Department of Agriculture, Harrow, Ontario, Canada.

Jeandet, P., Bessis, R., Sbaghi, M., and Meunier, P. 1995. Production of the phytoalexin resveratrol by grapes as a response to Botrytis attack under natural conditions. J. Phytopathol. 143:135-139.

Katzmann, D. J., Burnett, P. E., Golin, J., Mahé, Y., and Moye-Rowley, W. S. 1994. Transcriptional control of the yeast PDR5 gene by the PDR3 gene product. Mol. Cell Biol. 14:4653-4661.

Katzmann, D. J., Hallstrom, T. C., Mahé, Y., and Moye-Rowley, W. S. 1996. Multiple Pdr1p/Pdr3p binding sites are essential for normal expression of the ATP binding cassette transporter protein-encoding gene PDR5. J. Biol. Chem. 271:23049-23054.

Kjaerulff, S., Dooijes, D., Clevers, H., and Nielsen, O. 1997. Cell differentiation by interaction of two HMG-box proteins: Mat1-Mc activates $\mathrm{M}$ cell-specific genes in S-pombe by recruiting the ubiquitous transcription factor Ste11 to weak binding sites. EMBO J. 16:4021-4033.

Kodama, O., Miyakawa, J., Akatsuka, T., and Kiyosawa, H. 1992. Sakuranetin, a flavanone phytoalexin from ultraviolet-irradiated rice leaves. Phytochemistry 31:3807-3809.

Kolaczkowski, M., Kolaczowska, A., Luczynski, J., Witek, S., and Goffeau, A. 1998. In vivo characterization of the drug resistance profile of the major $\mathrm{ABC}$ transporters and other components of the yeast pleiotropic drug resistance network. Microbiol. Drug Resist. 4:143-158.

Kozak, M. 1984. Compilation and analysis of sequences upstream from the translational start site in eukaryotic mRNAs. Nucleic Acids Res. 12:857-872.

Leroux, P., Chapeland, F., Giraud, T., Brygoo, Y., and Gredt, M. 1998. Resistance to sterol biosynthesis inhibitors and various other fungicides in Botrytis cinerea. Pages 297-304 in: Modern Fungicides and Antifungal Compounds II. H. Lyr, P. E. Russell, H.-W. Dehne, and H. D. Sisler, eds. Intercept, Andover, U.K.

Ligon, J. M., Hill, D. S., Hammer, P. E., Torkewitz, N. R., Hofmann, D., Kempf, H. J., and Van Pee, K. H. 2000. Natural products with antifungal activity from Pseudomonas biocontrol bacteria. Pest. Sci. 56:688-695.

Logemann, J., Schell, J., and Willmitzer, L. 1987. Improved method for the isolation of RNA from plant tissues. Anal. Biochem. 163:16-20.

Mahé, Y., Parle-McDermott, A., Nourani, A., Delahodde, A., Lamprecht, A., and Kuchler, K. 1996. The ATP-binding cassette multidrug transporter Snq2 of Saccharomyces cerevisiae: A novel target for the transcription factors Pdr1 and Pdr3. Mol. Microbiol. 20:109-117.

Miyahara, K., Hirata, D., and Miyakawa, T. 1995. Functional analysis of the promoter of the Saccharomyces cerevisiae multidrug resistance gene YDR1, which encodes a member of the ATP binding cassette (ABC) superfamily. Biosci. Biotechnol. Biochem. 59:147-149. 
Nakaune, R., Adachi, K., Nawata, O., Tomiyama, M., Akutsu, K., and Hibi, T. 1998. A novel ATP-binding cassette transporter involved in multidrug resistance in the phytopathogenic fungus Penicillium digitatum. Appl. Environ. Microbiol. 64:3983-3988.

Osbourn, A. E. 1999. Antimicrobial phytoprotectants and fungal pathogens: A commentary. Fungal Genet. Biol. 26:163-168.

Sambrook, J., F., Fritsch, E. F., and Maniatis, T. 1989. Molecular Cloning: A Laboratory Manual. 2nd ed. Cold Spring Harbor Laboratory, Cold Spring Harbor, NY, U.S.A.

Sanglard, D., Ischer, F., Monod, M., and Bille, J. 1997. Cloning of Candida albicans genes conferring resistance to azole antifungal agents: Characterization of $C D R 2$, a new multidrug $\mathrm{ABC}$ transporter gene. Microbiology 143:405-416.

Sbaghi, M., Jeandet, P., Bessis, R., and Leroux, P. 1996. Degradation of stilbene-type phytoalexins in relation to the pathogenicity of Botrytis cinerea to grapevines. Plant Pathol. 45:139-144.

Schafer, W., Straney, D., Ciuffetti, L., Etten, H. D. V., and Yoder, O. C. 1989. One enzyme makes a fungal pathogen, but not a saprophyte, virulent on a new host plant. Science 246:247-249.

Senior, A. E., Alshawi, M. K., and Urbatsch, I. L. 1995. The catalytic cycle of P-glycoprotein. FEBS Lett. 377:285-289.

Stehmann, C., and De Waard, M. A. 1995. Accumulation of tebuconazole by isolates of Botrytis cinerea differing in sensitivity to sterol demethylation inhibiting fungicides. Pestic. Sci. 45:311-318.
Stehmann, C., and De Waard, M. A. 1996. Sensitivity of populations of Botrytis cinerea to triazoles, benomyl and vinclozolin. Eur. J. Plant. Pathol. 102:171-180.

Urban, M., Bhargava, T., and Hamer, J. E. 1999. An ATP-driven efflux pump is a novel pathogenicity factor in rice blast disease. EMBO J. 18:512-521.

Van der Vlugt-Bergmans, C. J. B., Brandwagt, B. F., Van't Klooster, J. W., Wagemakers, C. A. M., and Van Kan, J. A. L. 1993. Genetic variation and segregation of DNA polymorphisms in Botrytis cinerea. Mycol. Res. 97:1193-1200.

Van Kan, J. A. L., Van't Klooster, J. W., Wagemakers, C. A. M., Dees, D. C. T., and Van der Vlugt-Bergmans, C. J. B. 1997. Cutinase A of Botrytis cinerea is expressed, but not essential, during penetration of gerbera and tomato. Mol. Plant-Microbe Interact. 10:30-38.

Van Tuyl, J. M. 1977. Genetics of fungal resistance to systemic fungicides. Meded. Landbouwhogesch. Wagening. 77:1-136.

Walker, J. E., Saraste, M., Runswick, M. J., and Gay, N. J. 1982. Distantly related sequences in the alpha- and beta-subunits of ATP synthase, myosin, kinases and other ATP-requiring enzymes and a common nucleotide binding fold. EMBO J. 1:945-51.

Ziogas, B. N., and Girgis, S. M. 1993. Cross-resistance relationships between benzimidazole fungicides and diethofencarb in Botrytis cinerea and their genetical basis in Ustilago maydis. Pestic. Sci. 39:199205. 